\title{
Decoding the Myths of the Native and Non-Native English Speakers Teachers (NESTs \& NNESTs) on Saudi EFL Tertiary Students
}

\author{
Noor Motlaq Alghofaili ${ }^{1} \&$ Tariq $_{\text {Elyas }}^{2}$ \\ ${ }^{1}$ English Language Institute, King Abdulaziz University, Jeddah, Saudi Arabia \\ ${ }^{2}$ European Langauges Department, King Abdulaziz University, Jeddah, Saudi Arabia \\ Correspondence: Tariq Elyas, European Langauge Department, King Abdulaziz University, Jeddah, Saudi Arabia. \\ E-mail: telyas@kau.edu.sa
}

\author{
Received: March 1, 2017 Accepted: April 1, 2017 Online Published: April 5, 2017 \\ doi: 10.5539/elt.v10n6p1 URL: http://doi.org/10.5539/elt.v10n6p1
}

\begin{abstract}
Many people believe the myth that being taught by a native speaker is the best way to learn a language. This belief has influenced many Saudi schools, language institutes, and universities to include the nativeness factor as part of a language instructor's job requirements. Using an open ended questionnaire, this study aims to investigate the impact of native English speaking teachers (NESTs) and non-native English speaking teachers (NNESTs) on EFL university Saudi students. It also explores how the teachers' background and accents influence the students' achievement in terms of the development of their language skills. The participants are students who are in their preparatory year program at King Abdulaziz University in Jeddah taught by NEST and NNEST. The findings of the study indicate that teachers' nativeness and backgrounds have no significant effects on the EFL Saudi students' learning processes. However, a few factors have been detected that play roles in supporting EFL learning, which can be summarized as follows: 1) Teachers' competence and experience are what make the teachers qualified, regardless of their nationalities. 2) Teachers sharing the students' L1 play positive roles in the EFL learning process. 3) The teacher's accent has an effect on students, which might hinder the learning process in the case of an unfamiliar accent. 4) The teacher's personality is more involved in the classroom communications and interactions than is the teacher's nativeness. Based on the findings of this study, implications are made on the topic of the effect of NEST and NNEST on EFL learning.
\end{abstract}

Keywords: native teacher, non-native teacher, teaching English, Saudi EFL context, teacher's impact

\section{Introduction}

\subsection{Background}

According to Al-Nawrasy (2013), when we usually hear "native speaker of English," we comprehend it as indicating a person whose first language is English and who has spoken it since early childhood. On the other hand, "non-native speaker of English" means one whose first language is not English and he/she learned it as a second or foreign language. Debates have been conducted for over 20 years to determine the ideal language teacher (Al-Nawrasy, 2013). It is commonly known that NESTs are considered the ideal language teacher (Moussu, 2010). This belief shaped the idea of hiring NESTs in schools, language centers, and even universities regardless of their teaching qualifications and experience (Alseweed, 2012). In fact, most of EFL instructors' job advertisements prefer NEST over NNEST (Selvi, 2010). According to Li-Yi (2011), in Taiwan, parents consider NNESTs incompetent due to their lack of overseas experience, regardless of their qualifications. Also, NESTs have more job offers than NNESTs, which creates more pressure on NNESTs.

Since a large number of countries now use English as their official language, the need for people across the world to learn English is becoming stronger every day. English is the dominate language in many fields such as business, science, education, and technology (Arvizu, 2014). As a result, the numbers of English language learners have rapidly increased the demands for qualified ESL teachers (Elyas \& Picard, 2013) . Studies have shown the majority of English language teachers are non-native speakers (Arvizu, 2014; Alseweed, 2012). Moreover, according to Medgyes (1999), the number of non-native English speakers is more than native speakers studying in EFL TESOL programs (cited in Moussu \& Llurda, 2008)

However, many studies have shown ESL students may prefer NNESTs for learning certain language skills 
(Alseweed, 2012; Ma \& Ping, 2012; Walkinshaw \& Oanh, 2014). In addition, according to Beckett and Stiefvater (2009), students enjoy learning from NNESTs in courses like presentation skills, mathematics, engineering, and business, especially from NNESTs who share their cultural background.

\subsection{Significance of the Study}

Most studies have been done within the context that English is used as a native language, like in the United States. In fact, few studies have been conducted in Arabian contexts (Al-Nawrasy, 2013). Since learning English language has become essential for university students as part of their higher education requirements, their preferences towards NESTs became stronger to fit their ideal way to acquire the English language through learning how to use it in communication (Alseweed \& Daif-Allah, 2012).

Since most of the studies were conducted according to teachers and students perceptions towards NEST and NNEST, very few studies have been conducted on the impact of NEST and NNEST on students in the Saudi context. Moreover, those studies conducted in the Saudi context included only male teachers' and the students' voice (Al-Omrani, 2008). Also, such Arabian studies are urgently needed, especially in Saudi Arabia where the education movement is rapidly increasing the demands for English courses to be a part of the university students' qualifications (Mahboob \& Elyas, 2014; Elyas \& Picard, 2013). This study can be very important for many reasons. First, it can draw a clear picture for the students, educators, and administrators about the ideal language instructor, regardless of nativeness. Second, it might help change the idea in Saudi Arabia "that foreign language should be taught by a native speaker of the language" (Alseweed, 2012) and give more job opportunities to teachers based on qualifications. Finally, it will help the administrators and decision makers in assigning the best tasks for NESTs and NNESTs, placing them where they can achieve higher goals.

\subsection{Purpose and Aim of the Study}

This study will investigate the impact of native English speaking teachers (NESTs) and non-native English speaking teachers (NNESTs) on EFL university Saudi students. It will also explore how the teachers' background and accents influence the students' achievements in terms of the development of their language skills. Additionally, this study will clarify if teachers' nativeness has a significant effect on factors that are essential to the learning process such as: assessments, classroom interaction and classroom management.

\section{Literature Review}

\subsection{Native vs. Non-Native General Perceptions}

According to Phillipson (1996), contrary to popular belief, the fact that non-native English speaking teachers (NNESTs) have acquired the language as an additional language makes them ideal ESL teachers (as cited in Alseweed, 2012). A study conducted by Beckett and Stiefvater (2009), in which 15 students were observed and interviewed, stated that students enjoyed being taught by NNESTs, especially ones who shared their cultural background and were more aware of their needs. According to a study in Hong Kong by Ma and Ping (2012), the interviews show that NNESTs can be more sensitive to students' learning problems and better anticipate their learning difficulties. Furthermore, survey questionnaires have indicated that NNESTs are good learner models, are more informative about the language, can use effective teaching strategies, and can predict learners' language difficulties (Moussu, 2010). NNESTs were described as enthusiastic, knowledgeable, informative, and conscious of students' needs (Alseweed \& Daif-Allah, 2012). Additionally, Pereira's (2009) triangulation techniques (questionnaire, interviews, and classroom observation) have affirmed that Arab students show positive attitudes towards ESL teachers who share their background and native language.

In contrast, according to Hertel and Sunderman's (2009) survey results, native English speaking teachers (NESTs) are more knowledgeable, and their teaching potential is much higher than that of NNESTs, which leads to an increase in the learning potential of students taught by NESTs. In addition, students are comfortable in their classes with NESTs, who are friendly and lenient, making the learning environment relaxing and less threatening (Alseweed, 2012). In addition, being taught by NESTs can be motivating to students who enjoy learning about other cultures (Walkinshaw \& Oanh, 2014).

However, teachers' effectiveness in motivating students and in giving them the chance to develop their skills is more important than the teachers' nativeness (de Dios Martínez Agudo \& Robinson, 2014). Using linguistic analysis of students' text, Lipovsky and Mahboob (2010) found that students do not really prefer NESTs or NNESTs, but they value the cooperation of NESTs and NNESTs in their English learning. A study conducted using a survey questionnaire in Vietnam by Walkinshaw and Oanh (2012) showed that there are factors more important than the teachers' nativeness, such as teaching experience, friendly personality, qualifications, students' cultural familiarity, and teaching styles. Many studies have also reported that a learner's experience, 
background, gender, and taste might influence their perceptions towards their teachers (Beckett \& Stiefvater, 2009).

\subsection{Native vs. Non-Natives in Terms of Skills and Teaching Abilities}

Many studies have reported similar findings regarding which teacher is considered the best in teaching certain skills. The literature indicates that NESTs are better at teaching skills, especially communicative skills (Al-Nawrasy, 2013). Alseweed and Daif-Allah (2012) found that NNESTs are considered better teachers of grammar and writing due to their knowledge of rules and structure, whereas NESTs are superior in teaching listening, speaking, and reading. According to Mahboob (2004), NNESTs are better at teaching reading, writing, grammar, and language-learning skills due to their cultural awareness and metalinguistic nature. Also, NESTs lack the competence that NNESTs have in explaining complex grammar and lexical rules (Walkinshaw \& Oanh, 2014). Beckett and Stiefvater (2009) also reported that students showed positive attitudes towards NNESTs teaching courses such as presentation skills, business, and mathematics. However, NESTs are found to be more focused on grammatical form and fast speech, whereas NNESTs are more concerned with the content and with encouraging students' self-expression (Kim, 2009). Kim (2009) also indicates that NNESTs provide less feedback to the students on specific grammatical areas. Whereas, NESTs sometimes depend on their grammatical intuition in teaching grammar, which cannot be relied on in all cases (Ma \& Ping, 2012).

\subsection{Native vs. Non-Natives in Terms of Accents and Fluency}

Butler (2007) reports that accent might very well influence students' attitudes towards their teachers. NESTs use of informal language in classrooms enhances students' learning and motivates them to learn the language (Alseweed \& Daif-Allah, 2012). Acceptance of foreign accents may vary according to Buckingham (2014), but accents are not very popular among students, especially accents that display regional variations. NESTs usually emphasize language fluency rather than accuracy, which explains their use of interactive activities that develop students' communicative competence (Alseweed \& Daif-Allah, 2012). Furthermore, students might lack motivation in speaking English with their NNESTs (Ma \& Ping, 2012). Finally, Mahmud and Ching (2012) stated that the more comprehensible the teacher's language, the more preferred the teacher is by students.

\subsection{Native vs. Non-Natives in Terms of Assessments and Evaluations:}

NESTs are found to be more lenient towards mistakes and more flexible in evaluating the students' progress (Alseweed, 2012; Alseweed \& Daif-Allah, 2012). According to Kim (2009), there is no significant difference in the way NESTs and NNESTs assist their students in oral performance. However, he found that NESTs provide detailed and elaborate comments when evaluating students, whereas NNESTs give general comments to their students regarding their performance. Moreover, Al-Nawrasy (2013) revealed that the difference between students who have been taught by NESTs and those taught by NNESTs can barely be perceived in their speaking exams.

\subsection{Native vs. Non-Natives in Arabian Context}

Very few studies have been conducted on NESTs and NNESTs in the Arabian context. A study was conducted on Saudi university's students using questionnaires, interviews, and classroom visits. This study reported that NNESTs were described as enthusiastic, knowledgeable, informative, and conscious of students' needs (Alseweed \& Daif-Allah, 2012). Using surveys and interviews on 169 EFL university students, Alseweed (2012) showed that higher-level students prefer NESTs in general and in terms of using different teaching strategies. However, students have reported positive feedback regarding NNESTs in terms of acknowledging their needs and providing a serious learning environment. In another study, similar techniques of questionnaire and interviews were used on 100 Saudi EFL/ESL students, revealing that teachers' qualifications and skills are highly appreciated without much attention being paid to teachers' backgrounds (Al-Omrani, 2008). In addition, results have also shown that a combination of the qualities of NESTs and NNESTs may lead to more effective EFL teaching programs. In a study by Buckingham (2014), 347 Omani students were asked to evaluate five speakers who were recorded twice and were labeled the first time as NNESTs and the second time as NESTs. The speakers were rated higher when assigned as NESTs, and the study showed that students had an overwhelming preference for a UK accent. A study by Al-Nawrasy (2013) discussed the effects of NESTs and NNESTs on students' achievements in speaking skills using a different methodology. He used an ex post facto design to explore possible effects of the teachers' native-ness on students' achievements in speaking skills. The study showed that students taught by NESTs acquire better pronunciation, whereas students of NNESTs are more accurate in using the language. 


\section{Research Design}

\subsection{Research Questions}

The present study is designed to answer the following research questions:

1) What is the effect of NESTs and NNESTs on EFL university Saudi students?

2) What is the influence of the teachers' nativeness, backgrounds, and accents on the students' achievements in speaking, listening, reading and writing?

3) Do NESTs and NNESTs have any significant effect on EFL university Saudi students with regards to assessments, classroom management, students' motivation, and student/teacher interaction?

\subsection{Methodology}

\subsubsection{Open-ended Questionnaire}

In applied linguistics research, questionnaires provide an opportunity to obtain information about aspects of the phenomenon that may be difficult to observe. It is one of the most popular instruments in such fields due to fact that it is flexible, easy to construct, and gathers a large amount of information in a short time (Dörnyei, 2007). Brown (2001) defines questionnaires as "any written instruments that present respondents with a series of questions or statements to which they are to react either by writing out their answers or selecting from among existing answers" (p. 6). According to, Cohen et al. (2007) "an open-ended question can catch the authenticity, richness, depth of response honesty and candour" (p. 330). In this study, an open-ended questionnaire was used to explore the impact of NESTs and NNESTs on students with regard to teaching skills, assessments, classroom management, student motivation, and student-teacher interaction. Beyond the fact that open-ended questionnaires are more economical and practical than interviews, the use of an open-ended questionnaire was undertaken mainly because most of the ELI students would not approve of audio recording, and the ELI does not encourage them to do so. Additionally, open-ended questions offer the opportunity to a larger number of participants to express their own thoughts and ideas, which can lead to unexpected and insightful data (Mackey \& Gass, 2005).

The questionnaire was based on insights gained from the review of literature. It was divided into two parts. The first part included questions that report the number of NESTs and NNESTs that students have encountered in their English learning experience and those teachers' nationalities. The second part included eight interview questions organized under three themes:

1) General perceptions regarding the impact of teacher's nativeness on English language learning.

2) The effect of NESTs and NNESTS on English-language teaching skills.

3) The effect of NESTs and NNESTs in terms of assessments, motivation, classroom management, and student-teacher interaction.

For the participants' convenience, the questionnaire was translated into their first language of Arabic.

\subsubsection{Participants and Sampling}

The study was conducted at The English Language Institute (ELI) at King Abdulaziz University (KAU) in Jeddah, Saudi Arabia. At ELI, freshmen students are enrolled in a preparatory year program (PYP), during which they have to complete four levels of English courses. The participants were 18 students, eight in Level 103 and 10 in Level 104. All students were taught by both types of teachers, native- and non-native-speaking. The participants' names were changed by the researcher into pseudonyms to protect their privacy. The teachers' nationalities investigated in the open-ended questionnaire were American, British, Canadian, Pakistani, Indian, Syrian, Jordanian, Malaysian, Egyptian, Turkish, and Saudi.

\subsubsection{Data Collection Procedures}

The ELI uses a modular system of four quarters per academic year. The data was collected during the third and fourth modules of the same year. An approval form to conduct the study was obtained from the Head of the Research Unit Department at the ELI at KAU. Consent forms were obtained from all students participating in the study. The consent forms were translated into Arabic to ensure the students' comprehension of the research study and then were given to each participant along with the original English text. The participants were also aware of the fact that their participation was voluntary. Confidentially and anonymity were assured to all participants; the right to withdraw from the study at any time was also granted. 


\section{Results}

Thematic analysis was used to analyze the open-ended questionnaire. The results were classified under three major themes, which are presented here.

\subsection{Theme 1: General Perceptions Regarding the Impact of the Teacher'S Nativeness on the English Language Learning Process}

Most of the participants believed that the teacher's nativeness has an effect on their learning process. However, they emphasized the effect of the teacher's accent and pronunciation, which can make it difficult for them to understand what the teacher is saying. Their preference did not support NEST or NNEST as long as they were familiar with the teacher's accent and pronunciation. Four students thought that the teacher's background had no effect on their English learning process as long as he or she was a competent, experienced teacher. Some participants did not like the teachers' unfamiliar accent rather than their background. This dislike came from the difficulty of understanding the English language. For instance, Maryam discussed the problems she faced in understanding the English of some of her teachers who came from one particular country. She stated: "I cannot understand my Indian teachers; their accent is very weird to me. I think that the teacher should acquire a familiar accent for the students, which will help them first psychologically and then educationally." Some students mentioned that it was very beneficial when the teacher shares the students' L1. They feel more comfortable and connected. Additionally, two students highlighted that NNESTs are more sympathetic and concerned about helping the EFL learners learn the language since they have been through the same EFL learning experience. At the same time, a participant implied that NESTs can have more communicative competence and knowledge of the language. However, another participant mentioned that NESTs can speak very fast, which makes it hard for the students to understand.

\subsection{Theme 2: The Effect of Native Speaking Teachers and Non-Native Speaking Teachers on Teaching English Language Skills:}

The quantitative data showed that the participants' responses to this theme discussed each language skill separately to have a clearer picture of what they think of the effect of their teacher's nativeness on their achievement. The language skills discussed in this theme are: reading, listening, speaking and writing.

\subsection{Reading Skill}

The participants' reactions toward reading skills varied. However, half of the participants preferred to learn reading from NESTs, while others praised the NNESTs' method of using reading strategies and techniques in their teaching. They also emphasized that translating into L1 and code switching can be very beneficial when the teacher speaks the same language as the students. Very few participants stated that there was no difference between NESTs and NNESTs in teaching reading as long as they were competent and used basic reading strategies in their teaching.

\subsection{Listening Skill}

As for listening skills, the participants' attitudes toward the effect of the teacher's nativeness on teaching listening skills varied between two replies: (1) there is no difference between the two teachers and (2) NNEST is better than NEST in teaching listening. Only two participants highlighted the superiority of NESTs in teaching listening, which was due to their correct pronunciation.

However, some participants implied that both types of teachers can be good as long as they have acquired correct pronunciation. As for the group that supported NNESTs, they justified their choice with many reasons. The first main reason was that NESTs speak very fast, which makes it very difficult for the students to understand what they are saying. Laila explained: "For NESTs, the English language is very easy and simple because they are used to it; this makes them speak quickly, not realizing the difficulty students usually face in learning the English language." Kholoud added: "NESTs speak very fast, which makes it very hard to understand, especially for the beginner level." Another reason is that NNESTs are more considerate about the struggle that the students experience in developing their English listening skills and also recognize their students' weaknesses better than NESTs. Additionally, NNESTs use better strategies and techniques in teaching EFL listening skills. To the students, NNESTs are more understanding, particularly when the teacher shares their L1.

\subsection{Speaking Skill}

In regards to teaching speaking skills, less than half the participants stated that NESTs are superior to NNESTs. However, no clear justification for their choice was made by any of these participants, except one who mentioned that NESTs provide a better pronunciation model for the students, which helps them improve their 
pronunciation and speaking.

Six other participants replied that there is no difference between NESTs and NNESTs in teaching speaking, especially if the NNESTs share their L1. They asserted that the teacher's background has no effect on their process of learning speaking skills as long as the teacher is competent, experienced, and has acquired understandable English pronunciation.

On the other hand, four participants showed their preference for NNESTs in teaching speaking. They explained that NNESTs can be more considerate of the difficulties EFL students usually have in speaking the English language, which helps the students to be less anxious about speaking and practicing the language in class. Also, the factor of sharing the L1 was highlighted by emphasizing that those NNESTs are more aware of the Arabic-speaking students' struggle in pronouncing some English sounds, so they work hand-in-hand with the students to overcome any speaking obstacles they might face. One last reason for their preference of NNESTs was that NESTs speak faster, which makes it difficult for the students to pick up the correct pronunciation and learn to use the language, whereas NNESTs speak slower and use repetition drills with their students.

\subsection{Writing Skill}

Similar replies were reported by the participants regarding the effect of NESTs and NNESTs in teaching writing skills. Almost all of the participants stated that there was no difference between learning writing from NESTs or NNESTs. For instance, Hana said: "There won't be any difference between NESTs and NNESTs in teaching writing as long as the teacher is competent." Participants who had different opinions did not provide any justification for their choice; two of them preferred NESTs and one preferred NNESTs.

4.7 Theme 3: The Effect of Native Speaking Teachers and Non-Native Speaking Teachers in Terms of Assessment and Exams, Motivation to Learn the Language, Teacher/Student Interaction, and Classroom Management.

This theme discusses factors that might be affected by a teacher's nativeness, such as: assessment and exams, motivation and encouragement, teacher/student interaction, and classroom management. The students' opinions regarding each factor will be discussed separately.

\subsection{Assessment and Exams}

In this section, the comparison between NESTs and NNESTs tackles the assessment factor by comparing the number of exams and quizzes both types of teachers give and whether they are lenient or strict with grading. Most of the participants agreed that there was no difference between NESTs and NNESTs in terms of assessment. They implied that it depends on the teachers' personalities, regardless of their backgrounds. On the other hand, six participants highlighted that NNESTs are more lenient when it comes to grading. Mona stated: "NNESTs are more sensitive to students' needs to get better grades, which makes them more helpful and lenient in grading, especially if they speak Arabic." One participant highlighted that NESTs give more quizzes and exams to the students than NNESTs.

\subsection{Motivation and Encouragement}

Eleven participants highlighted that there was no difference between NESTs and NNESTs in motivating and encouraging their students to learn the language. Ahlam said: "I don't think that there is a difference between NEST and NNEST in encouraging the students. I think it depends on the teacher's personality rather than background." Six other participants emphasized that NNESTs are better motivators for students to learn the language since they have gone through the same EFL learning experience as a student. Moreover, one participant mentioned that NESTs have the ability to motivate the students and support them with continuous encouragement.

\subsection{Teacher/Student Interaction and Classroom Management}

This section discusses the relationship between the teacher and students in terms of communication, classroom interaction, and classroom management. NNESTs were found to be more connected to their students. Nine participants reported that they are easy to communicate with, especially if they share their L1. Mona said: "I prefer to communicate with NNESTs because they understand me better and they provide me with good feedback and tips that can help me learn the language." NNESTs were also described as having good classroom management skills. A few participants claimed that NESTs can interact with their students easily. Also, the fact that the only way to communicate with their teacher was by using the English language has improved their English and motivated them to learn. They were also praised for the amount of activities and games they use in their teaching. The last six participants agreed that there was no difference between NESTs and NNESTs in their interactions with their students. They believed that each teacher has his or her own teaching style and techniques 
that is used to interact with the students whether he or she is native or non-native.

\section{Discussion}

\subsection{What Are the Different Effects of NESTs and NNESTs on Saudi EFL University Students?}

According to the data analysis of this study, no significant effect of the NESTs and NNESTs on Saudi EFL university students has been highlighted. Thus, it has been emphasized that teachers' accents may have more effects on students' English language learning rather than teacher's nativeness. Additionally, it has been indicated that teachers with unclear and unfamiliar accents make the English language difficult to understand, which hinders the language learning process. Saudi EFL university students showed acceptance of the teachers with familiar accents, which are the native accents and the accents of the teachers sharing their L1, and reject any other accents. This finding supports the existing literature which indicates that students are more motivated and open to learning with teachers speaking with native accents (Butler, 2007; Kelch \& Santana-Williamson, 2002; Ma \& Ping, 2012; Moussu, 2006).

Last point is that there are no effects of NESTs and NNESTs as long as the teacher is competent and experienced. This is in line with Walkinshaw and Oanh's (2012) findings, which stated that there are other factors that are more important than teacher's nativeness such as teaching experience, approachable personality, qualifications, familiarity with students' cultures, and teaching styles.

Also, teachers' sharing the students' L1 is highly appreciated in providing a comfort zone for the students' language learning by giving a sense of connection between the teacher and the students (Alseweed \& Daif-Allah, 2012; Moussu, 2010).

5.2 What is the Influence of the Teachers' Nativeness, Background, and Accents on Their Students' Achievement in Reading, Listening, Speaking, and Writing?

To answer this research question, the discussion will be divided into four subsections. In each subsection, one skill will be discussed individually to reflect the influence of the teachers' nativeness on that specific skill.

\subsection{Reading Skill}

According to the data in this study, many students prefer NEST in teaching reading skill, which is contrary to Al-Omrani (2008) and Mahboob (2004) who stated that NNESTs were considered more effective in teaching reading. However, NNESTs were highlighted for using reading strategies and techniques in line with the findings of Al-Omrani (2008), who revealed that NNESTs are able to teach their students the reading strategies needed to overcome their reading challenges. Along with Lasagabaster and Sierra (2005), only a few participants believed that teachers' nativeness has no influence on students' achievements in reading skills.

\subsection{Listening Skill}

According to the data, participants emerged with two different opinions: first, that there is no difference between NESTs and NNESTs in teaching listening; whereas, the other participants believed that NNESTs are better at teaching listening. This point disagrees with what is found in the literature, which indicates that NESTs are better at teaching listening as they are the ideal models for authentic life (Al-Omrani, 2008; Kelch \& Santana-Williamson, 2002; Lasagabaster \& Sierra, 2005; Mahboob, 2004; Nam, 2010). In this study, the reasons provided for NNESTs' superiority in teaching listening can be summarized as:

- NESTs are described as speaking very fast.

- NNESTs are more considerate about students' struggles in listening skills.

- $\quad$ NNESTs are better at recognizing students' learning weaknesses.

- $\quad$ NNESTs who share the students' L1 play important roles in the students' listening learning processes.

\subsection{Speaking Skill}

Students have different perceptions regarding which type of teacher they prefer to teach them speaking. Students who prefer NESTs did not justify their choice, which might indicate that their choice could be affected by the Native Speaker Fallacy (Philipson, 1992). However, such findings were widely found in literature in which students prefer NESTs to teach them speaking (Al-Omrani, 2008; Kelch \& Santana-Williamson, 2002; Lasagabaster \& Sierra, 2005; Mahboob, 2004). Still, a few students justified their choice by stating they believe that NESTs provide better pronunciation models for the students; this agrees with Omrani (2008), who stated that NESTs were preferred to teach speaking due to their accurate fluency and pronunciation. On the other hand, some students expressed their preferences for NNESTs because they share their L1, which plays an effective role in giving students a sense of security and encouragement to speak the language. Also, NNESTs are found to be 
more aware of students' struggles in speaking L2. Such findings contradict Benke and Medgyes' (2005) results, which revealed that NESTs are good motivators for students to speak the L2. Lastly, NESTs were found to speak fast, which creates difficulties for students in learning speaking; this is in line with Ma and Ping (2012) and Sung (2010).

\subsection{Writing Skill}

As for writing skills, the data revealed that participants think that NESTs and NNESTs has no influence on students in terms of teaching writing skill, which contradicts literature that states NNESTs are more favored by students in teaching writing (Al-Omrani, 2008; Alseweed \& Daif-Allah, 2012; Mahboob, 2004).

5.7 Do NESTs and NNESTS Have Any Significantly Different Effects on Saudi EFL University Students with Regard to Assessments, Student Motivation, Classroom Management, and Student-Teacher Interactions?

According to data, no significant effect of NEST and NNEST has been detected on Saudi students in general with regard to assessments, student motivation, classroom management, and student-teacher interactions. In terms of assessment, the participants claimed that a teacher's personality is more likely to influence the assessment process than is his or her background. Such results are in line with the previous studies of Kim (2009) and of Lasagabaster and Sierra (2005), which indicate that there is no difference between NESTs and NNESTs in terms of assessments. However, the participants in this study implied that NNESTs can be more lenient in terms of grading. This result does not agree with Kim's (2009) finding, which states that NESTs are more lenient toward mistakes and more flexible in evaluations.

In terms of motivation and encouragement, the findings also highlighted that teachers' nativeness does not have a remarkable role in motivating students. However, the fact that NNESTs share the same EFL learning experience as the students sometimes represents them as better motivators to the students. This is similar to Al-Omrani's (2008) finding that NNESTs appreciate and praise hard-working students more than do NESTs. NNESTs are also found to be more connected to the students and more strongly encourage their self-expression (Kim, 2009). On the other hand, NESTs were found to be a source of motivation for students who enjoy learning about other cultures (Walkinshaw \& Oanh, 2014).

The findings of the influences of NESTs and NNESTs on teacher/student interactions and classroom management have not been very different than the previously-mentioned factors. Similarly, the findings implied no significant differences between NESTs and NNESTs in terms of teacher/student interactions and classroom management.

However, NNESTs were given a few privileges in such terms, which are summarized as follows:

- $\quad$ NNESTs are usually more connected to the students.

- $\quad$ NNESTs are easier to communicate with, especially when sharing L1.

- $\quad$ NNESTs have more classroom management skills.

In Alseweed (2012), NESTs were described as lenient and as making the learning environment relaxing and less threatening, while in this same study NNESTs were identified as better in classroom management. Furthermore, in other research, NNESTs were found to provide a more relaxed learning environment (Alseweed \& Daif-Allah, 2012; da Silva, 2009; Ma \& Ping, 2012; Moussu, 2010). Lastly, similar to the current study findings, participants in Al-Omrani's study (2008) highlighted that being taught by NNESTs sharing L1 is more comfortable for them, especially when receiving feedback and asking questions.

\section{Conclusion}

Per the findings of this study and their possible interpretations, it could be concluded that teachers' nativeness and backgrounds have no significant effects on EFL Saudi students' learning processes. However, a few factors have been detected that play roles in supporting EFL learning, which can be summarized as follows:

1) Teachers' competence and experience are what make the teachers qualified, regardless of their nationalities.

2) Teachers sharing the students' L1 play positive roles in the EFL learning process.

3) The teacher's accent has an effect on students, which might hinder the learning process in the case of an unfamiliar accent.

4) The teacher's personality is more involved in the classroom communications and interactions than is the teacher's nativeness.

Even though we conclude that no remarkable influences of a teacher's nativeness and background have been 
found in the study, still a variety of results have occurred that favor both NESTs and NNESTs in different situations.

\section{Implications of the Study}

According to the findings presented in this study, the following implications can be useful for research, teacher's identity, stakeholders, and language teachers' hiring systems. As mentioned in the first chapter of this thesis, the Native Speaker Fallacy (Philipson, 1992) has had an impact on EFL/ESL students, administrators, hiring system, and non-native teachers' self-recognitions.

As a result, this research explores the differences in the effects of NESTs and NNESTs on Saudi EFL learners' achievements and on their perceptions about their teachers. This study states that no significant effect has been observed on students' achievements in the four language skills. Moreover, it was highlighted that teacher/student interactions, students' motivation, and classroom communication and management are not affected by the teacher's nativeness but rather by the teacher's qualifications and personality. Such findings imply that EFL learners in Saudi Arabia have no clear preference for either NESTs or NNESTs, just like the ESL learners who were found by Mahboob (2004) to appreciate both types of teachers with their unique tributes. This study's findings demonstrate the need for equality in hiring practices in EFL learning. In line with Mahboob (2004), NNESTs were found by students to have more strong points, unlike NESTs, who received no clear preferences except for their accents and pronunciation. In this study, students highlighted their preferences for the native accent due to the struggles they encountered when taught by NNESTs who come from a country other than their own with unclear and unfamiliar accents. The students' emphasis on pronunciation can be interpreted, according to Mahboob (2004), as a reason for a hiring preference of NESTs over NNESTs; there is the thought that they make better teachers, while in fact it is simply that they acquire clear accents and pronunciation, which can also be acquired by NNESTs.

Students also mentioned some good qualities of NNESTs, such as high appreciation of sharing L1 with their teachers. This shows that Saudi students are not falling under the Native Speaker Fallacy and that they acquire high levels of awareness in appreciating the collaboration of the two types of teachers. The students' statements that a good teacher is a function of his or her competence and experience highlight the fact that the administration and hiring system should pay more attention to a teacher's accent, qualifications, experience, competence, and personality rather than the teacher's nationality.

\section{Limitations of the Study}

Despite the contributions and implications of some aspects of this study, it still has some limitations and shortcomings. The first and major limitation is the narrow range of the EFL learners and teachers represented by the study. The findings from the students' perceptions about their teachers represent the opinions of only a small number of students (18 students). Furthermore, all participants came from same Saudi background in two advanced language levels (level 3 and level 4). Therefore, the findings are considered primary and are difficult to generalize to the wider context of EFL teaching, locally or globally. Additionally, due to the cultural and social considerations, this study was bound to a particular milieu, the EFL female students, since it was difficult for the researcher to include the male students and conduct the study on them.

\section{Recommendations for Further Study}

The findings of the current study suggest that teachers' nativeness has no impact on EFL students' learning processes. However, several areas remain that warrant continued investigation to develop further insightful understanding of the topic. Here are some recommendations for future study:

1) It will be crucially important to have more participants (both students and teachers) in order to run more complex statistical analyses and to reveal more significant results.

2) It would be more valuable if we compared students' achievements in language skills among more than two classes taught by more than two teachers.

3) The results from this research may prompt future research to investigate the effects of teachers' sharing students' L1.

4) Research conducted on the impact of accents on EFL students is highly recommended.

5) Different EFL settings can be very beneficial in comparative research.

\section{References}

Al-Nawrasy, O. (2013). The effect of native and non-native English language teachers on secondary students' 
achievement in speaking skills. Jordan Journal of Educational Sciences, 9(2), 243-254.

Al-Omrani, A. H. (2008). Perceptions and attitudes of Saudi ESL and EFL students toward native and nonnative English-speaking teachers. ProQuest.

Alseweed, M. A. (2012). University students' perceptions of the influence of native and non-native teachers. English Language Teaching, 5(12), 42-53. https://doi.org/10.5539/elt.v5n12p42

Alseweed, M. A., \& Daif-Allah, A. S. (2012, July). University students' perceptions of the teaching effectiveness of native and nonnative teachers of English in the Saudi context. Language In India, 12(7), 35.

Arvizu, M. N. G. (2014). Students' beliefs and expectations of native and non-native English teachers. Mextesol Journal, 38(3), 1405-3470.

Beckett, G. H., \& Stiefvater, A. (2009). Change in ESL graduate students' perspectives on non-native English-speaker teachers. TESL Canada Journal, 27(1), 27-46. https://doi.org/10.18806/tesl.v27i1.1028

Benke, E., \& Medgyes, P. (2005). Differences in teaching behavior between Native and non-native speaker teachers Non-native Language Teachers. In E. Llurda (Ed.), Non-native language teachers: Perceptions, challenges and contributions to the profession (pp. 195-215). New York, NY: Springer. https://doi.org/10.1007/0-387-24565-0_11

Brown, J. D. (2001). Using surveys in language programs. Cambridge, UK: Cambridge University Press.

Buckingham, L. (2014). Recognizing English accents in the community: Omani students' accent preferences and perceptions of nativeness. Journal of Multilingual and Multicultural Development, (ahead-of-print), 1-16.

Butler, Y. G. (2007). How are nonnative - English - speaking teachers perceived by young learners? Tesol Quarterly, 41(4), 731-755. https://doi.org/10.1002/j.1545-7249.2007.tb00101.x

Cohen, L., Manion, L., \& Morrison, K. (2007). Research methods in education (6 $6^{\text {th }}$ ed.). New York: Routledge.

de Dios Martínez Agudo, J., \& Robinson, I. (2014). Native or non-native? The nativeness factor from the EFL student teachers' perspective Utrecht Studies in Language \& Communication, 27.

Dörnyei, Z. (2007). Research methods in applied linguistics: Quantitative, qualitative, and mixed methodologies. Oxford: Oxford University Press.

Mahboob, A., \& Elyas, T. (2014). English in Saudi Arabia: A Historical and Linguistics Analysis. World Englishes, Vol. 33 (1),12-35.

Elyas, T., \& Picard, M. (2013). Critiquing of higher education policy in Saudi Arabia: towards a newneoliberalism. Education, Business and Society: Contemporary Middle Eastern Issues, 6(1), 3-41. https://doi.org/10.1108/17537981311314709

Hertel, T. J., \& Sunderman, G. (2009). Student attitudes toward native and non-native language instructors. Foreign Language Annals, 42(3), 468-482. https://doi.org/10.1111/j.1944-9720.2009.01031.x

Kelch, K., \& Santana-Williamson, I. E. (2002). ESL students' attitudes toward native- and nonnative-speaking instructors' accents. The CATESOL Journal, 14(1), 57-72.

Kim, Y. H. (2009). An investigation into native and non-native teachers' judgments of oral English performance: A mixed methods approach. Language Testing, 26(2), 187-217. https://doi.org/10.1177/0265532208101010

Lasagabaster, D., \& Sierra, J. M. (2005). What do students think about the pros and cons of having a native speaker teacher? In E. Llurda (Ed.), Non-native language teachers: Perceptions, challenges and contributions to the profession (pp. 217-241). New York, NY: Springer Science+ Business. https://doi.org/10.1007/0-387-24565-0_12

Lipovsky, C., \& Mahboob, A. (2010). STUDENTS'APPRAISAL OF THEIR NATIVE AND NON-NATIVE ENGLISH-SPEAKING TEACHERS. WATESOL NNEST Caucus Annual Review, 1, 119-154

Li-Yi, W. (2011). Taiwanese pre-service English teachers' attitude towards native-English-speaking-teachers and native-and-non-native-English-speaking-teacher team teaching. English Teaching \& Learning, 35(2), 1-46.

Ma, F., \& Ping, L. (2012). Advantages and disadvantages of native and non-native-English-speaking teachers: Student perceptions in Hong Kong. TESOL Quarterly, 46(2), 280-305. https://doi.org/10.1002/tesq.21

Mackey, A., \& Gass, S. M. (2005). Second language research: Methodology and design. Mahwah, NJ: Lawrence Erlbaum.

Mahboob, A. (2004). Native or nonnative: What do students enrolled in an intensive English program think? In L. 
D. Kamhi-Stein (Ed.), Learning and teaching from experience (pp. 121-148). Ann Arbor, MI: University of Michigan Press.

Mahmud, M. M., \& Ching, W. S. (2012). The attitude and perceptions of transfer students towards non-native speakers English lecturers. Educational Sciences.

Moussu, L. (2006). Native and non-native English-speaking as a second language teachers: Student attitudes, teacher self-perceptions, and intensive English program administrator beliefs and practices (Unpublished doctoral dissertation). Purdue University, West Lafayette, IN.

Moussu, L. (2010). Influence of teacher - contact time and other variables on ESL students' attitudes towards native and non-native-English-speaking teachers. TESOL Quarterly, 44(4), 746-768. https://doi.org/10.5054/tq.2010.235997

Moussu, L., \& Llurda, E. (2008). Non-native English-speaking English language teachers: History and research. Language Teaching, 41(03), 315-348. https://doi.org/10.1017/S0261444808005028

Nam, H. H. (2010). The Pedagogy and Its Effectiveness among Native and Non-Native English Speaking Teachers in the Korean EFL Context (Unpublished doctoral dissertation). State University of New York at Buffalo, Buffalo, NY.

Pereira, d. S. (2009). Students' expectations and attitudes towards nonnative-english-speaking teachers in ESL and EFL settings: Teachers' and students' own perspectives. ProQuest Dissertations \& Theses Full Text; ProQuest Dissertations \& Theses Global, 305027630.

Selvi, A. F. (2010). All teachers are equal, but some teachers are more equal than others: Trend analysis of job advertisements in English language teaching.WATESOL NNEST Caucus Annual Review, 1, 156-181.

Sung, C. C. M. (2010). Native or non-native? Exploring Hong Kong students' perspectives. Papers from the Lancaster University Postgraduate Conference in Linguistics \& Language Teaching, 4, 243

Üstünlüoglu, E. (2007). University students' perceptions of native and non - native teachers. Teachers and Teaching: theory and practice, 13(1), 63-79. https://doi.org/10.1080/13540600601106096

Walkinshaw, I., \& Oanh, D. H. (2014). Native and non-native English language teachers: Student perceptions in Vietnam and Japan. SAGE publication. https://doi.org/10.1177/2158244014534451

Walkinshaw, I., \& Oanh, D.H. (2012). Native or non-native English speaking teachers in Vietnam: Weighing the benefits. TESL-EJ.

\section{Copyrights}

Copyright for this article is retained by the author(s), with first publication rights granted to the journal.

This is an open-access article distributed under the terms and conditions of the Creative Commons Attribution license (http://creativecommons.org/licenses/by/4.0/). 